\title{
Measurement of S-glutathionylated proteins by HPLC
}

\author{
Daniela Giustarini $^{1}$ (D) Aldo Milzani ${ }^{2} \cdot$ Isabella Dalle-Donne $^{2} \cdot$ Ranieri Rossi $^{1}$
}

Received: 27 March 2021 / Accepted: 29 May 2021 / Published online: 15 June 2021

(c) The Author(s) 2021

\begin{abstract}
$S$-glutathionylated proteins (GSSP), i.e., protein-mixed disulfides with glutathione (GSH), are considered a suitable biomarker of oxidative stress. In fact, they occur within cells at low level and their concentration increases markedly under pro-oxidant conditions. Plasma is something different, since it is physiologically rich in $S$-thiolated proteins (RSSP), i.e., protein-mixed disulfides with various types of low molecular mass thiols (LMM-SH). However, albumin, which is largely the most abundant plasma protein, possesses a cysteine residue at position 34 that is mostly reduced (about 60\%) under physiological conditions, but easily involved in the formation of additional RSSP in the presence of oxidants. The quantification of GSSP requires special attention to sample handling, since their level can be overestimated as a result of artefactual oxidation of GSH. We have developed the present protocol to avoid this methodological problem. Samples should be treated as soon as possible after their collection with the alkylating agent $N$-ethylmaleimide that masks -SH groups and prevents their oxidation. The GSH released from mixed disulfides by reduction with dithiothreitol is then labeled with the fluorescent probe monobromobimane and quantified by HPLC. The method can be applied to many different biological samples, comprising blood components, red blood cell plasma membrane, cultured cells, and solid organs from animal models.
\end{abstract}

Keywords $S$-glutathionylation $\cdot$ HPLC $\cdot$ Whole blood $\cdot$ Cells $\cdot$ Protocols $\cdot$ Quantification

\begin{tabular}{|c|c|}
\hline \multicolumn{2}{|c|}{ Abbreviations } \\
\hline CyGlySSP & $\begin{array}{l}\text { Protein mixed disulfides with cysteinyl } \\
\text { glycine }\end{array}$ \\
\hline CySSHb & $S$-Cysteinylated hemoglobin \\
\hline CySSP & $S$-Cysteinylated proteins \\
\hline DTT & Dithiothreitol \\
\hline$\gamma$-GluCySSP & $\begin{array}{l}\text { Protein mixed disulfides with } \\
\gamma \text {-glutamylcysteine }\end{array}$ \\
\hline$\gamma \mathrm{GT}$ & $\gamma$-Glutamyl transpeptidase \\
\hline GSH & Glutathione \\
\hline GSSG & Glutathione disulfide \\
\hline GSSP & $S$-Glutathionylated proteins \\
\hline HbSSG & $S$-Glutathionylated hemoglobin \\
\hline
\end{tabular}

Handling editor: D. Tsikas.

Daniela Giustarini

daniela.giustarini@unisi.it

1 Department of Biotechnology, Chemistry and Pharmacy (Department of Excellence 2018-2022), Laboratory of Pharmacology and Toxicology, University of Siena, Via A. Moro 4, 53100 Siena, Italy

2 Department of Biosciences (Department of Excellence 2018-2022), Università Degli Studi Di Milano, via Celoria 26, I-20133 Milan, Italy

$\begin{array}{ll}\text { HcySSP } & S \text {-Homocysteinylated proteins } \\ \text { HD } & \text { Hemodialysis } \\ \text { LMM-SH } & \text { Low molecular mass thiols } \\ \text { mBrB } & \text { Monobromobimane } \\ \text { NEM } & N \text {-Ethylmaleimide } \\ \text { NGAL } & \text { Neutrophil gelatinase-associated lipocalin } \\ \text { PBS } & \text { Phosphate-buffered solution } \\ \text { PRP } & \text { Platelet-rich plasma } \\ \text { P-SH } & \text { Protein thiol groups } \\ \text { RBCs } & \text { Red blood cells } \\ \text { ROS } & \text { Reactive oxygen species } \\ \text { RSSP } & S \text {-Thiolated proteins } \\ t \text {-BOOH } & \text { tert-Butyl hydroperoxide } \\ \text { TCA } & \text { Trichloroacetic acid }\end{array}$

\section{Introduction}

Protein thiol groups (P-SH) can be present in biological systems in different redox forms, one of which is represented by mixed disulfides with low molecular mass thiols (LMM$\mathrm{SH}$ ), also defined as $S$-thiolated proteins (RSSP). More than 95\% of RSSP within cells is represented by $S$-glutathionylated proteins (GSSP). The tripeptide glutathione (GSH) 
occurs at millimolar concentration within all mammalian cells (Hansen et al. 2009; Giustarini et al. 2017). The -SH group of the cysteine moiety confers to GSH a high reactivity towards a plethora of compounds. By reaction with oxidants, GSH can be converted to its disulfide forms, i.e., glutathione disulfide (GSSG) and GSSP. GSSP can form either by direct reaction with reactive oxygen species (ROS) or by reaction with secondary products of oxidative stress such as GSSG (Dalle-Donne et al. 2008). The susceptibility of P-SH to form mixed disulfides with LMM-SH depends on both the solvent accessibility of the thiol within the threedimensional structure of the protein and the redox potential of the Cys residue.

GSSP have been investigated essentially for two main reasons. First of all, they are considered a good biomarker of oxidative stress in addition to GSSG. Inside mammalian cells, GSH exists almost totally in the reduced form, but both GSSG and GSSP can increase during oxidative perturbations (Schafer et al. 2001). Additionally, it is worth noting that, whereas GSSG is rapidly reduced by glutathione reductase, GSSP are less prone to enzymatic reduction (Giustarini et al. 2019). Second, $S$-glutathionylation is a post-translational modification of cysteine residues that can regulate protein functions by allosteric modification of their conformation. Therefore, $S$-glutathionylation of sensitive proteins can lead to a change in the activity or function of the oxidized protein, thus suggesting a role in physiological signaling (Grek et al. 2013). Moreover, since $S$-glutathionylation is a reversible process, it has been regarded as a protective mechanism against irreversible P-SH oxidation to sulfinic/sulfonic acids (Schafer et al. 2001).

Thus, only accessible P-SH with high thiol-disulfide oxidation potential are likely to undergo $S$-glutathionylation under physio-pathological conditions. For example, $S$-glutathionylated hemoglobin has attracted interest as a clinical biomarker of oxidative stress. Human hemoglobin has an accessible Cys residue in position $\beta 93$ (Garel et al. 1982) that occurs almost totally in the reduced form in healthy people but that it is supposed to be $S$-glutathionylated under specific pathological conditions, such as diabetes mellitus and Friederich ataxia (Niwa 2007; Piemonte et al. 2001). Albumin too possesses a free Cys in position 34 that can form mixed disulfides with LMM-SH (Sengupta et al. 2001). In contrast to the intracellular environment, the concentration of GSH in plasma is low $(\sim 2 \mu \mathrm{M})$ and other LMM-SH are present, namely cysteine, cysteinyl glycine, homocysteine, and $\gamma$-glutamylcysteine. Under physiological conditions, about $60 \%-70 \%$ of Cys 34 in plasma albumin occurs as a free thiol, whereas the remaining Cys34 residues are involved in the formation of mixed disulfides with the physiological plasma LMM-SH (Sengupta et al. 2001; Turell et al. 2013). It is hypothesized that the percentage of $S$-thiolated albumin can increase in some diseases where oxidative stress has a role in the onset and/or progression of the disease (Candiano et al. 2009).
In vitro experiments with whole blood, red blood cells (RBCs), platelets, or cultured cells showed that GSSP increase rapidly under pro-oxidant conditions, i.e., after treatment with peroxides, diamide, disulfiram, or menadione (Rossi et al. 2001, 2006b; Giustarini et al. 2015). Moreover, GSSP concentration is found to be age-dependent in several rat tissues (Giustarini et al. 2011).

We must point out that this field of research is plagued by several pre-analytical artifacts, which usually lead to a large overestimation of GSSP. It is evident that, to better understand and define the physio-pathological role of GSSP, you need to pay attention to the methodological procedure used to detect them. We have demonstrated that -SH groups can be artefactually oxidized during sample handling in the pre-analytical step, thus raising the levels of both GSSG and GSSP (Rossi et al. 2002). This methodological problem should be particularly taken into consideration when the analysis of intracellular GSSP is carried out. In fact, the higher the real ratio GSH/ GSSP, the higher the artificial increase in measured GSSP.

The protocol we describe and discuss here is commonly applied in our laboratory for GSSP quantification in cells and tissues. It has been developed to minimize all possible pre-analytical problems related to artificial oxidation of the -SH group with consequent overestimation of GSSP.

\section{Materials}

\section{Chemicals and reagents}

Acetonitrile (HPLC-grade) Sigma-Aldrich \# 34851

Acivicin

Sigma-Aldrich \# A2295

Boric acid

Sigma-Aldrich \# B6768

Bovine serum albumin

Bradford reagent

Sigma-Aldrich \#A3294

Supelco \#B6916

Brij® L23 solution

Sigma-Aldrich \# B4184

Disodium hydrogen phosphate Sigma-Aldrich \# 30412

Dithiothreitol Millipore \# 111474

Drabkin's reagent Sigma-Aldrich, \# D 5941

Glacial acetic acid (HPLC-grade) EMD Millipore Chemicals \# AX0074

l-Glutathione, reduced $\quad$ Sigma-Aldrich \# G4251

HPLC Zorbax Eclipse XDB-C18 column $4.6 \times 150 \mathrm{~mm}$, $5 \mu \mathrm{m}$

Human hemoglobin

Agilent Technologies

Hydrochloric acid 37\%

Methanol (HPLC-grade)

Monobromobimane

Sigma-Aldrich \# H7379

Sigma-Aldrich \# 320331

Sigma-Aldrich \# 34860

Millipore \# 596105

$N$-ethylmaleimide

Sigma-Aldrich \# E1271

Phosphate buffer solution 1.0 M pH 7.4 Sigma-Aldrich

\# P3619 
Potassium dihydrogen phosphate Sigma-Aldrich, \# 229806

L-Serine Sigma-Aldrich \# S4500

Sodium chloride Sigma-Aldrich \# S7653

Sodium hydroxide solution, $2 \mathrm{M}$ Fluka \# 35254

Trichloroacetic acid

Sigma-Aldrich \# T6399

Tripotassium EDTA

Fluka \# 03664

Tris base

Sigma-Aldrich \# T1503

Water (HPLC-grade)

\section{Equipment}

The chromatographic separations reported in this article were performed using an HPLC Agilent 1100 series with fluorometric detector (Agilent Technologies). For each set of analyses, the column was first conditioned with $100 \%$ mobile phase B (HPLC-grade acetonitrile), $1.2 \mathrm{ml} / \mathrm{min}$ for at least $5 \mathrm{~min}$, and the temperature equilibrated at $25^{\circ} \mathrm{C}$. Then, the mobile phase composition was changed to $94 \%$ phase A (sodium acetate $0.25 \%(\mathrm{v} / \mathrm{v}) \mathrm{pH} 3.10$ ) and $6 \%$ phase B. Run conditions: $0-5^{\prime} 6 \%$ phase B, 5' $-10^{\prime}$ ' gradient until $10 \%$ phase B, $10^{\prime}-10^{\prime} 50$ ' $10 \%$ phase B. The injection volume was $10 \mu \mathrm{l}$. After each injection, at the end of the run, the column was flushed with $100 \%$ phase B for $2 \mathrm{~min}$, and then, the system was re-equilibrated to the initial isocratic conditions before the subsequent injection. The signals were recorded setting excitation at $390 \mathrm{~nm}$ and emission at $480 \mathrm{~nm}$. Retention times: Cys $=4.18 \mathrm{~min}$, CysGly $=5.27 \mathrm{~min}$, Hcys $=8.31 \mathrm{~min}$, and GSH $=10.1 \mathrm{~min}$. The retention factor for GSH is 4.

The determination of the protein content was performed by a UV-Vis spectrophotometer (Jasco, V-550).

\section{Small laboratory equipment}

1. PD-10 desalting columns, bed volume $3.5 \mathrm{ml}$.

2. Semi-micro disposable cuvettes (Kartell, code 1938).

3. Microcentrifuge tubes, $1.5 \mathrm{ml}$ (Eppendorf or equivalent).

4. Microcentrifuge (Mini Spin, Eppendorf).

5. Vortex 3 (IKA) with test tube inset.

6. Homogenizers (Potter Elvehjem P7859 or IKA Ultraturrax with $\mathrm{S} 10 \mathrm{~N}-8 \mathrm{G}$ dispersing element).

7. HPLC vials (Agilent Technologies).

8. $\mathrm{pH}$ meter.

\section{Stock and working solutions}

A. $310 \mathrm{mM}$ NEM: dissolve $388 \mathrm{mg} N$-ethylmaleimide in $10 \mathrm{ml}$ water.

B. $100 \mathrm{mM} \mathrm{NaCl} / 20 \mathrm{mM}$ phosphate buffer $\mathrm{pH}$ 7.4: dissolve $584 \mathrm{mg} \mathrm{NaCl}$ in $2 \mathrm{ml} 1.0 \mathrm{M}$ phosphate buffer solution and $98 \mathrm{ml}$ water.

C. $20 \mathrm{mM}$ Tris base: prepare $2 \mathrm{M}$ Tris base by dissolving $24.2 \mathrm{~g}$ Tris in $100 \mathrm{ml}$ water and then dilute it 1:100 in water.

D. $100 \mathrm{mM} \mathrm{NaCl} / 20 \mathrm{mM}$ Tris base: dissolve $584 \mathrm{mg}$ $\mathrm{NaCl}$ in $1 \mathrm{ml} 2 \mathrm{M}$ Tris base and make the volume up to 100 $\mathrm{ml}$ with water.

E. $0.1 \mathrm{M}$ phosphate buffer $\mathrm{pH}$ 6.5: dissolve $0.95 \mathrm{~g} \mathrm{KH}_{2} \mathrm{PO}$ and $0.427 \mathrm{~g} \mathrm{Na}_{2} \mathrm{HPO}_{4}$ in $80 \mathrm{ml}$ water. Adjust the $\mathrm{pH}$ to 6.5 and make the volume up to $100 \mathrm{ml}$.

F. $5 \mathrm{mM}$ phosphate buffer $\mathrm{pH}$ 6.5/NEM: prepare $10 \mathrm{ml}$ buffer by mixing $0.5 \mathrm{ml} 0.1 \mathrm{M}$ phosphate buffer $\mathrm{pH} 6.5$, $0.065 \mathrm{ml} 310 \mathrm{mM} \mathrm{NEM}$ and $9.43 \mathrm{ml}$ water.

G. PBS/NEM: mix $9.73 \mathrm{ml}$ of normal saline solution (normal saline solution; $9 \mathrm{~g}$ of $\mathrm{NaCl}$ per liter), $0.065 \mathrm{ml}$ $310 \mathrm{mM}$ NEM and $0.2 \mathrm{ml}$ of $1 \mathrm{M}$ phosphate buffer $\mathrm{pH}$ 7.4.

H. TCA solutions: all the TCA solutions are prepared by diluting $60 \% \mathrm{w} / \mathrm{v}$ trichloroacetic acid (60 g TCA brought to a final volume of $100 \mathrm{ml}$ with water).

I. Tris-BSAN: prepare $50 \mathrm{mM}$ Tris buffer in water with serine/boric acid/acivicin/NEM (pH 8.0). Dissolve $3.03 \mathrm{~g}$ of Tris in $430 \mathrm{ml}$ of water and add $0.62 \mathrm{~g}$ of boric acid, $105 \mathrm{mg}$ of serine, $2 \mathrm{mg}$ of acivicin and $50 \mathrm{ml}$ of $310 \mathrm{mM}$ NEM. Adjust the $\mathrm{pH}$ to 8.0 with $1 \mathrm{M} \mathrm{HCl}$; adjust the volume to $500 \mathrm{ml}$ with water.

L. $0.5 \mathrm{M}$ Tris $\mathrm{pH} 7.8$ containing $1 \mathrm{mM} \mathrm{K}_{3}$ EDTA: dissolve $3 \mathrm{~g}$ Tris in $30 \mathrm{ml}$ water. Add $22 \mathrm{mg} \mathrm{K} \mathrm{E}_{3}$ EDTA, adjust the $\mathrm{pH}$ at 7.8 , and make the volume up to $50 \mathrm{ml}$.

M. 10 mM DTT: dissolve $15.4 \mathrm{mg}$ dithiothreitol in $10 \mathrm{ml}$ water.

N. $40 \mathrm{mM} \mathrm{mBrB}$ : dissolve $10.8 \mathrm{mg}$ monobromobimane in $1 \mathrm{ml}$ methanol.

O. Mobile phase A (solution for HPLC): prepare $1 \mathrm{~L}$ of $0.25 \%$ (vol/ $\mathrm{vol}$ ) acetic acid by diluting $2.5 \mathrm{ml}$ of glacial acetic acid with HPLC-grade water. Add a few drops of $2 \mathrm{M}$ $\mathrm{NaOH}$ to bring the $\mathrm{pH}$ to 3.1 .

\section{Protocol}

\section{General aspects}

The protocol presented here has been developed to measure the total GSSP content in cells and tissues. It is based on the quantification of GSH released by reduction of GSSP. The main steps required for the application of the methods are shown in Fig. 1. A key step in GSSP analysis is the separation of proteins by the application of easy and time-saving methods. This step is usually carried out by acidification, followed by protein separation by centrifugation. However, we thoroughly demonstrated that the use of acids induces artificial oxidation of thiols to disulfides 


\section{Blood components}

Collect $\sim 3 \mathrm{ml}$ of whole blood, add immediately $+300 \mu 1$ of $310 \mathrm{mM}$ NEM

Whole blood cells

$\rightarrow$ lyse $0.2 \mu 1$ of whole blood by addition of water.

$\rightarrow$ centrifuge to separate membranes

$\rightarrow$ desalt the supernatant

$\rightarrow$ reduce disulfides and measure delivered GSH by HPLC

\section{Red blood cells}

$\rightarrow$ wash whole blood three times with PBS

$\rightarrow$ lyse $100 \mu 1$ of packed RBCs by addition of water

$\rightarrow$ centrifuge to separate membranes.

$\rightarrow$ desalt the supematant

$\rightarrow$ reduce disulfides and measure delivered GSH by HPLC

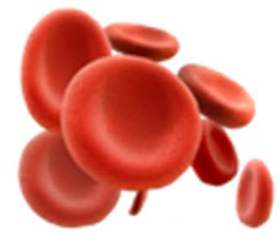

\section{Cell membranes}

$\mathrm{A} \rightarrow$ wash membranes and centrifuge

$\rightarrow$ repeate this step for three times

$\rightarrow$ reduce disulfides and measeure delivered GSH by HPLC

\section{White blood cells}

$\rightarrow$ centrifuge $1 \mathrm{ml}$ of whole blood

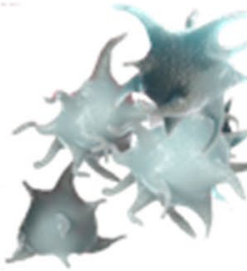

Platelets

$\rightarrow$ centrifuge whole blood to separate platelet rich plasma (PRP)

$\rightarrow$ wash the platelets with PBS

$\rightarrow$ add TCA and centrifuge to spun proteins

$\rightarrow$ wash protein pellets

$\rightarrow$ resuspend pellet, reduce disulfides and measure delivered GSH

$\rightarrow$ discard PRP, which is stratified in the upper part of the tube

$\rightarrow$ collect the buffy coat, which lies over RBCs

$\rightarrow$ wash buffy coat with PBS

$\rightarrow$ centrifuge and discard the supernatant

$\rightarrow$ add to the pellet $1.5 \mathrm{ml}$ of a RBC lysing solution

$\rightarrow$ centrifuge and discard the supernatant

$\rightarrow$ add TCA and centrifuge to spun proteins

$\rightarrow$ resuspend pellets, reduce disulfides and measure delivered GSH

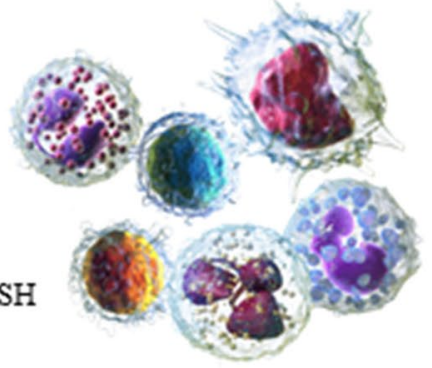

Plasma

$\rightarrow$ centrifuge $500 \mu 1$ of whole blood

$\rightarrow$ add $1 \mathrm{ml}$ of $3 \%(\mathrm{w} / \mathrm{v})$ TCA to $100 \mu \mathrm{l}$ of the supernatant

$\rightarrow$ centrifuge $2 \mathrm{~min}$ at $10,000 \times$ gto spun proteins

$\rightarrow$ wash protein pellet

$\rightarrow$ resuspend pellets, reduce disulfides and measure delivered thiols by HPLC

\section{Solid tissues from animal models}

$\rightarrow$ remove the organ(s)/tissue and wash them with saline.

$\rightarrow$ weight the tissues and homogenize them in Tris-BSAN buffer

$\rightarrow$ add TCA and centrifuge to spun proteins

$\rightarrow$ resuspend pellets, reduce disulfides and measure delivered GSH by HPLC

\section{Cell cultures}

$\rightarrow$ remove the culture medium and wash cells

$\rightarrow$ lyse the cells with TCA

$\rightarrow$ collect the cells by scraping

$\rightarrow$ centrifuge to spun proteins

$\rightarrow$ wash protein pellets

$\rightarrow$ resuspend pellets, reduce disulfides and measure delivered GSH by HPLC

Fig. 1 Schematic diagram of the main steps for RSSP detection in biological samples. The scheme describes the main pre-analytical steps required for RSSP detection in RBC plasma membrane, in the

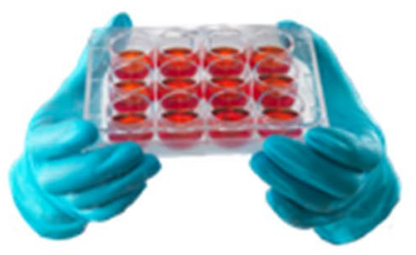

cytoplasm of blood components, cell cultures, and solid tissues, and in plasma. The delivered GSH (or LMM-SH for plasma samples) is then quantified by fluorometric HPLC 
(Rossi et al. 2002). As a consequence, a fair amount of artificial GSSP can be formed during this phase. Even if this artifact can be limited by addition of chelating agents (e.g., EDTA) or the use of TCA instead of perchloric acid or metaphosphoric acid, we reported that also under these conditions, it cannot be avoided (Rossi et al. 2002). Since the cytoplasmic concentration of GSH is usually two or three orders of magnitude greater than that of GSSP, a minimal percentage of oxidation leading to the production of GSSP causes a massive artificial alteration of their levels. In a few words, the measured concentrations of intracellular GSSP are not physiological, but are mostly due to an artifact. We experienced this issue, in particular, when working with RBCs, probably due to the presence of iron and oxygen bound to hemoglobin, which during acidification formed reactive oxygen species (ROS) (Rossi et al. 2002). However, a treatment with an agent that can quickly block all free thiols before any further processing can solve the problem. We proved that the alkylating agent $N$-ethylmaleimide (NEM) is perfect for this purpose. This molecule was shown to easily cross membranes and to rapidly bind all present -SH groups, thus preventing their oxidation during sample handling (Rossi et al. 2002). Therefore, a common aspect of this protocol is the sample pre-treatment with NEM, which should be done as soon as possible after its collection. The excess of NEM can be easily removed by performing several washings of protein pellet under slight acidic conditions. At the end of this procedure, after the elimination of any trace of soluble GSH, a purified protein pellet is obtained, ready to undergo the proper treatment for the release of proteinbound GSH. An exception is the detection of $S$-glutathionylated hemoglobin (HbSSG) in RBCs. For detecting $\mathrm{HbSSG}$, we separate the protein by gel-filtration to remove excess NEM, GSH, and GSSG at once (Giustarini et al. 2003). This procedure is preferred to the use of washed acid precipitated proteins as we noted that, after restoring neutral $\mathrm{pH}$, the presence of a massive amount of denatured hemoglobin induces oxidation of the reducing agent used to detach GSH from GSSP, hampering a precise and accurate measurement of GSSP. Also, GSSP from RBC plasma membrane can be measured, because membrane separation is a preparative step performed before gel filtration. For this purpose, membranes are washed three times with PBS to eliminate GSH and GSSG before further processing.

The homogenization buffer for GSSP analyses in solid tissues must be slightly alkaline to speed up the alkylation of all -SH groups with NEM. However, the presence of $\gamma$-glutamyl transpeptidase $(\gamma \mathrm{GT})$ may present a challenge, because it can not only decompose soluble GSH but also GSSP. We obviate this potential drawback by including the $\gamma \mathrm{GT}$ inhibitors borate, serine, and acivicin into the homogenization buffer.
For the cleavage of the $\mathrm{S}-\mathrm{S}$ bridge, a solution of dithiothreitol (DTT) at slight alkaline $\mathrm{pH}$ is used. GSH released from GSSP is then labeled with monobromobimane $(\mathrm{mBrB})$ and quantified by HPLC.

It is worthy of note that this procedure can detect not only GSSP but also protein-mixed disulfides with other LMMSH. This is particularly useful when analyzing plasma samples, where several different LMM-SH are bound to albumin (Sengupta et al. 2001). Conversely, in the intracellular milieu, GSSP represent almost $100 \%$ of mixed disulfides present under both physiological conditions and oxidative stress conditions.

We report here, in detail, the procedure to measure GSSP in animal solid organs, but the same can be applied to human tissues. As for blood samples, the protocol for human samples is described, but it can be applied to blood samples from virtually all animal species too. Nevertheless, since rat hemoglobin can form precipitates when handled at low $\mathrm{pH}$ (Brunori et al. 1982), a specific procedure is described accordingly.

\section{Biological samples and preparative procedure}

For the analyses in blood components collect $\sim 3 \mathrm{ml}$ of whole blood from the antecubital vein into $\mathrm{K}_{3}$ EDTA vacutainers and add immediately $300 \mu \mathrm{l}$ of $310 \mathrm{mM}$ NEM. Invert gently the tubes for 10 times and then apply the procedure described below for the specific kind of blood component.

\section{Whole blood}

Cytosolic whole blood GSSP: lyse $0.2 \mathrm{ml}$ of whole blood by addition of three volumes of water.

Centrifuge at $15,000 \times g$ for $10 \mathrm{~min}$ to separate membranes. Desalt the supernatant with PD-10 columns equilibrated with $100 \mathrm{mM} \mathrm{NaCl}$ containing $20 \mathrm{mM} \mathrm{Na}{ }^{+} / \mathrm{K}^{+}$phosphate buffer $\mathrm{pH}$ 7.4. Eluted sample is ready for analysis or can be stored at $-80{ }^{\circ} \mathrm{C}$ for up to 6 months.

!WARNING: since rat hemoglobin crystallizes in hypoosmotic buffers, for cell lysis and desalting buffer a $20 \mathrm{mM}$ Tris base solution and a $20 \mathrm{mM}$ Tris base solution containing $100 \mathrm{mM} \mathrm{NaCl}$ are used, respectively.

Cell membrane GSSP from whole blood: centrifuge cell lysates as above described at $15,000 \times g$ for $10 \mathrm{~min}$ to separate membranes. Wash membranes with $5 \mathrm{mM} \mathrm{Na} / \mathrm{K}^{+}$phosphate buffer pH 6.5 containing 2 mM NEM. Repeat this step three times suspending each time membrane pellet with a glass rod. Membrane samples are now ready for analysis or can be stored at $-80{ }^{\circ} \mathrm{C}$ for up to 6 months. 


\section{Red blood cells}

Cytosolic RBC GSSP: purify RBCs by washing three times $400 \mu \mathrm{l}$ of whole blood with $1 \mathrm{ml}$ of PBS containing $2 \mathrm{mM}$ of NEM. Then lyse $100 \mu \mathrm{l}$ of packed RBCs by addition of three volumes of water (or $20 \mathrm{mM}$ Tris base for rat RBCs). Centrifuge at $15,000 \times g$ for $10 \mathrm{~min}$ to separate membranes. Desalt the supernatant with PD-10 columns equilibrated with $100 \mathrm{mM} \mathrm{NaCl}$ containing $20 \mathrm{mM}$ $\mathrm{Na}^{+} / \mathrm{K}^{+}$phosphate buffer $\mathrm{pH} 7.4$ (or $20 \mathrm{mM}$ Tris base for rat $\mathrm{RBCs}$ ). Eluted sample is ready for analysis or can be stored at $-80{ }^{\circ} \mathrm{C}$ for up to 6 months.

Cell membrane GSSP: wash the membrane pellets obtained as above described with $5 \mathrm{mM} \mathrm{Na}{ }^{+} / \mathrm{K}^{+}$phosphate buffer pH 6.5 containing $2 \mathrm{mM}$ NEM. Repeat this step three times suspending each time membrane pellet with a glass rod. Membrane samples are now ready for analysis or can be stored at $-80{ }^{\circ} \mathrm{C}$ for up to 6 months.

\section{Washed platelets}

Centrifuge $1.5 \mathrm{ml}$ of whole blood at $4200 \times g$ for $40 \mathrm{~s}$ to separate platelet-rich plasma (PRP), which is stratified in the upper part of the tube. Collect PRP carefully avoiding the buffy coat, which lies over RBCs. Wash three times the platelets with $1 \mathrm{ml}$ PBS containing $2 \mathrm{mM} \mathrm{NEM}$ and, after the third washing, discard the supernatant and add $1 \mathrm{ml}$ of $3 \%$ (w/v) TCA. Mix well and centrifuge for $2 \mathrm{~min}$ at $14,000 \times g$. Repeat this step for three times resuspending with a glass rod. Finally, discard the supernatant. Samples are now ready for analysis or can be stored at $-80^{\circ} \mathrm{C}$ for up 6 months.

\section{White blood cells}

Centrifuge $1 \mathrm{ml}$ of whole blood at $4200 \times g$ for $40 \mathrm{~s}$ to separate PRP, which is stratified in the upper part of the tube. Collect the buffy coat, which lies over RBCs. Add $1 \mathrm{ml}$ of PBS containing $2 \mathrm{mM}$ NEM and centrifuge $30 \mathrm{~s}$ at $10,000 \times g$. Discard the supernatant and add to the pellet $1.5 \mathrm{ml}$ of an RBC lysing solution $(0.1 \mathrm{M}$ sodium chloride in $0.05 \mathrm{M} \mathrm{Na}^{+} / \mathrm{K}^{+}$phosphate buffer $\mathrm{pH}$ 7.4). Allow to settle for $30 \mathrm{~min}$, then centrifuge for $5 \mathrm{~min}$ at $10,000 \times g$ and discard the supernatant. This step eliminates RBCs collected along with the buffy coat. Add $1 \mathrm{ml}$ of $3 \%$ (w/v) TCA, mix well and centrifuge for $2 \mathrm{~min}$ at $14,000 \times \mathrm{g}$. Repeat this step for three times resuspending with a glass rod each time. Discard the supernatant. Samples are now ready for analysis or can be stored at $-80^{\circ} \mathrm{C}$ for up 6 months.

\section{Plasma}

Centrifuge $500 \mu \mathrm{l}$ of whole blood at $10,000 \times g$ for $20 \mathrm{~s}$. Add to $100 \mu \mathrm{l}$ of the supernatant $1 \mathrm{ml}$ of $3 \%$ (w/v) TCA. Centrifuge $2 \mathrm{~min}$ at $10,000 \times g$. Discard the supernatant and wash three times with $1 \mathrm{ml}$ of $3 \%(\mathrm{w} / \mathrm{v})$ TCA resuspending each time the pellet with a glass rod. Finally, discard the supernatant. Samples are now ready for analysis or can be stored at $-80{ }^{\circ} \mathrm{C}$ for up 6 months.

\section{Cell cultures}

Remove the culture medium and wash cells twice ( $1 \mathrm{~min}$ each) at room temperature with PBS/NEM. Lyse the cells by treatment with $1 \mathrm{ml}$ of $4 \%(w / v)$ TCA. Collect the cells by scraping. Mix well and centrifuge for $2 \mathrm{~min}$ at $14,000 \times \mathrm{g}$. Discard the supernatant and repeat this step for three times resuspending with a glass rod each time. Finally, discard the supernatant. Samples are ready for analysis or can be stored at $-80{ }^{\circ} \mathrm{C}$ for up to 6 months.

\section{Solid tissues from animal models}

Collect the blood from the anesthetized animal through the abdominal aorta, and during the withdrawal infuse $10 \mathrm{ml}$ of saline containing $5 \mathrm{mM}$ NEM through the inferior cava vein. After that collect and rapidly wash the organ(s)/tissue with ice-cold saline.

Weight the tissues and homogenize them 1: $10(\mathrm{w} / \mathrm{v})$ in Tris-BSAN buffer, wait for 1 min and then acidify by $1: 1$ addition of $10 \%(\mathrm{w} / \mathrm{v})$ TCA. Mix well and centrifuge for $2 \mathrm{~min}$ at $14,000 \times g$. Repeat this step for three times resuspending with a glass rod. Finally, discard the supernatant. Samples are ready for analysis or can be stored at $-80{ }^{\circ} \mathrm{C}$ for up to 6 months.

\section{Validation of the method}

An exemplificative chromatogram obtained by the analysis of RSSP in RBCs' membrane and plasma is reported in Fig. 2. The accuracy and the precision of the procedure were tested by addition of standard solutions of HbSSG prepared as previously described (Giustarini et al. 2015) and analyzed on three separate days. The precision of the method was expressed as the relative standard deviation (RSD) and was always well below 5\%. The accuracy was expressed as relative error (RE) [(mean observed concentration - spiked concentration)/(spiked concentration) $] \times 100 \%$ and ranged from -1.35 to $2.34 \%$ (intraday accuracy) and from -2.84 to $1.63 \%$ (interday accuracy).

The quantification limit of the method is $5 \mathrm{pmol} / \mathrm{mg}$ protein. 


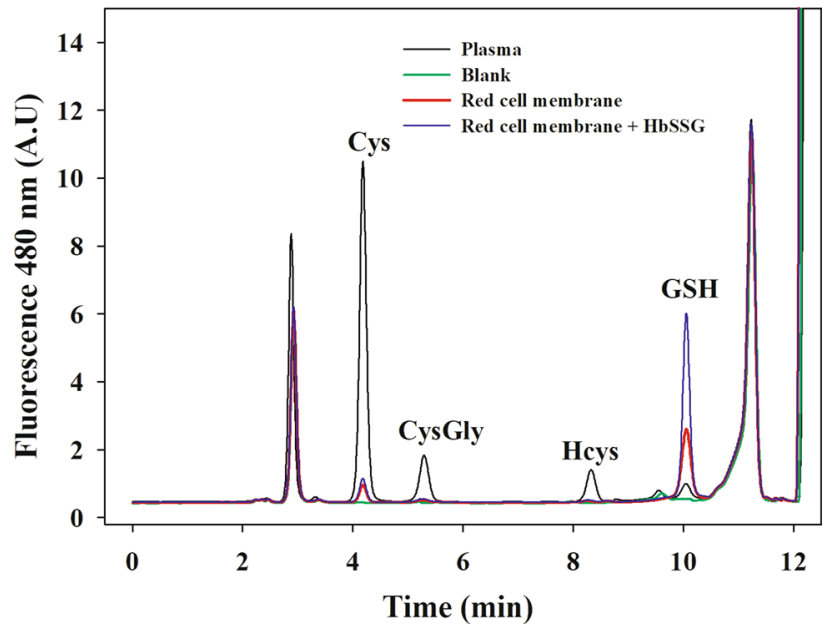

Fig. 2 Chromatogram showing the RSSP content in some biological samples. LMM-SH released by dithiothreitol cleavage are labeled with monobromobimane and separated by HPLC. A typical chromatogram is shown for GSSP in red blood cell plasma membrane and for RSSP in plasma. An exemplificative chromatogram obtained for RBC membrane samples added with a standard solution of $S$-thiolated hemoglobin (HbSSP, $2 \mathrm{nmol} / \mathrm{g} \mathrm{Hb}$ ) is reported too. The blank chromatogram refers to the analysis of a sample prepared with all the reagents but without the RBC membranes

\section{RSSP reduction and derivatization for HPLC analysis}

A. Plasma, washed platelets, white blood cells, cultured cells, solid tissues, whole blood, and RBC membranes.

Timing: $30 \mathrm{~min}$.

1. Resuspend pellet with $0.4 \mathrm{ml}$ of $0.075 \mathrm{M}$ TRIS base containing $1 \mathrm{mM}$ EDTA and $1 \mathrm{mM}$ DTT.

2. Put the samples in a gyratory shaker for $20 \mathrm{~min}$.

3. Deproteinize $0.1 \mathrm{ml}$ sample by acidification with $40 \mu \mathrm{l} 60 \%$ (w/v) TCA.

4. Centrifuge $2 \mathrm{~min}$ at $10,000 \times \mathrm{g}$.

5. React $0.1 \mathrm{ml}$ supernatant with $5 \mu \mathrm{l}$ of $40 \mathrm{mM} \mathrm{mBrB}$ and $20 \mu \mathrm{l} 2 \mathrm{M}$ TRIS base for $10 \mathrm{~min}$ in the dark.

6. Add $5 \mu \mathrm{l} \mathrm{37 \%} \mathrm{(v/v)} \mathrm{HCl}$.

7. Centrifuge $2 \mathrm{~min}$ at $10,000 \times \mathrm{g}$.

Samples are ready for HPLC analysis.

B. Whole blood and RBC cytosolic fractions.

Timing: $30 \mathrm{~min}$.

1. React $0.1 \mathrm{ml}$ protein fraction separated by gel filtration or purified membranes with $5 \mu$ of $10 \mathrm{mM}$ DTT for $15 \mathrm{~min}$.

2. Add $5 \mu \mathrm{l}$ of $40 \mathrm{mM} \mathrm{mBrB}$.

3. Place the sample in the dark for $15 \mathrm{~min}$.

4. Deproteinize the sample by addition of $10 \mu \mathrm{l}$ of $60 \%$ (w/v) TCA.

Samples are ready for HPLC analysis.

\section{Quantification by HPLC}

Timing: about 15 min per sample.

Chromatographic separation is performed on an Agilent series 1100 HPLC device with a Zorbax Eclipse XDB-C18 column and fluorometric detector.

Determination of concentration is performed by running standard concentrations of GSH (or other LMM-SH for plasma analyses).

\section{Normalization for protein content}

The normalization for protein content is carried out for whole blood, RBCs, membrane, white blood cells, and cultured cells analyses.

The concentration of hemoglobin in RBCs is obtained by colorimetric determination at $540 \mathrm{~nm}$ using the Drabkin's reagent. The reagent is prepared according to the manufacturer's instructions by dissolving it with Brij ${ }^{\circledR} \mathrm{L} 23$ solution. Human hemoglobin is used as a standard.

The protein concentration in RBC membranes, cultured cells, white blood cells, and whole blood is determined by colorimetric reaction with the Bradford reagent (Bradford 1979). Protein pellets are resuspended in $0.1 \mathrm{~N} \mathrm{NaOH}$ and mixed in a rotatory shaker to facilitate protein dissolving. An aliquot of the sample (typically $10 \mu \mathrm{l}$ ) is reacted with the Bradford reagent and analyzed at $595 \mathrm{~nm}$ wavelength. Bovine serum albumin is used as a standard.

Platelets values are normalized for cell count and solid tissue values for tissue weight.

\section{Biomedical applications}

\section{RSSP in RBCs}

The protocol described in this manuscript for the detection of GSSP in RBCs as biomarkers of oxidative stress was applied in our laboratory to human and rat samples. In Table 1, the reference values for both cytoplasmic and membrane GSSP are reported. It is evident that the basal levels of intracellular GSSP are usually very low, being about 2-3 orders of magnitude lower than cytoplasmic GSH concentration (Giustarini et al. 2003; Khazim et al. 2013). These values largely differ from those reported by other research groups (Table 2). We believe that this discrepancy is driven primarily by lack of standardization for properly addressing the technical challenge of GSH oxidation during sample collection. This makes it harder to compare results and slows down the advancement of knowledge in the field of research. Membrane GSSP occur at low levels in healthy people too (Giustarini et al. 2003). However, we have recently demonstrated that membrane 
Table 1 Values for GSSP measured in different blood components

\begin{tabular}{|c|c|c|c|}
\hline \multirow[t]{2}{*}{ Sample } & \multicolumn{2}{|l|}{ Red blood cells } & \multirow[t]{2}{*}{ References } \\
\hline & $\begin{array}{l}\text { Cytoplasmic } \\
\text { nmol/g Hb }\end{array}$ & $\begin{array}{l}\text { Membrane } \\
\mathrm{nmol} / \mathrm{g} \text { protein }\end{array}$ & \\
\hline Healthy humans $(n=12)$ & $9.90 \pm 3.02$ & $0.736 \pm 0.159$ & Giustarini et al. (2003) \\
\hline Healthy humans $(n=21)$ & $13 \pm 0.3$ & & Khazim et al. (2013) \\
\hline HD patients $(n=33)$ & $20 \pm 0.5$ & & Khazim et al. (2013) \\
\hline Rat $(n=10)$ & $10.5 \pm 2.57$ & $0.682 \pm 0.259$ & Giustarini et al. (2003) \\
\hline \multicolumn{4}{|l|}{ Platelets } \\
\hline Healthy humans $(n=5)$ & $0.046 \pm 007 \mathrm{nmol} / 10^{9} \mathrm{plt}$ & & Giustarini et al. (2016) \\
\hline \multicolumn{4}{|c|}{ White blood cells (cytoplasmic + membrane) } \\
\hline Healthy humans $(n=10)$ & $37.7 \pm 12.4 \mathrm{nmol} / 10^{6}$ cells & & Unpublished results \\
\hline
\end{tabular}

Data are the mean $\pm \mathrm{SD}$
Table 2 Levels of HbSSP measured in human blood from healthy people

\begin{tabular}{lll}
\hline $\mathrm{nmol} / \mathrm{mg} \mathrm{Hb}$ & Age & Reference \\
\hline $1050 \pm 660(n=15)$ & $49 \pm 7.6$ & Mandal et al. (2007) \\
$1230 \pm 100(n=20)$ & - & Naito et al. (1999) \\
$1000 \pm 530(n=20)$ & $47 \pm 10$ & Takayama et al. (2001) \\
$1287(n=41)$ & $55.7 \pm 12.8$ & Schepens et al. (2006) \\
$880 \pm 300$ & 43 & Muscat et al. (2004) \\
$200(n=9)$ & - & Al-Abed et al. (2001) \\
$166 \pm 450(n=30)$ & $11.4 \pm 3.73$ & Pastore et al. (2012) \\
$4380 \pm 2010$ & $23.4 \pm 6.5$ & Chen et al. (2014) \\
\hline
\end{tabular}

Data are expressed as nmoles/g $\mathrm{Hb}$ normalized for $\mathrm{Hb}$ content for comparison by considering a mean concentration of $150 \mathrm{mg} / \mathrm{ml}$ whole blood

GSSP concentration can increase more than that of cytoplasmic GSSP in RBCs under slight and intermittent oxidative conditions, which can mimic the physiological ones. In Fig. 3, the in vitro treatment of RBCs with a cyclic low concentration of tert-butyl hydroperoxide $(t-\mathrm{BOOH})$ slowly delivered with a particular device is reported. $t$-BOOH induced a stepwise increase of both HbSSG and membrane GSSPs; nevertheless, membrane GSSP appear to be less influenced by the absence of the peroxide. As a matter of fact, membrane GSSP decreased more slowly than $\mathrm{HbSSG}$ when $t$-BOOH infusion was stopped, suggesting that membrane GSSP decreased slowly when prooxidant conditions are absent. It should also be noted that the oxidant-induced membrane GSSP were more abundant than HbSSG at all the analyzed times (Giustarini et al. 2019). Interestingly, as reported in Fig. 3, under slight intermittent oxidative stress GSSG appears to rise and decrease much faster than both membrane and cytosolic GSSP, thus suggesting that HbSSG and even more membrane GSSP are stable biomarkers of oxidative stress, which are likely less affected than GSSG by either temporary variation of oxidant stimulus or sample manipulation.

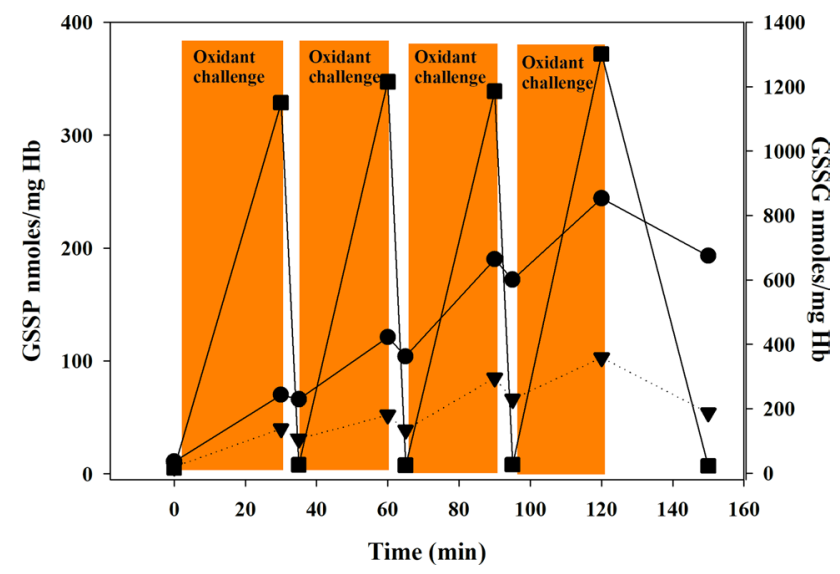

Fig. 3 Cytoplasmic and membrane GSSP and GSSG in RBCs treated with $t$-BOOH. RBCs at a $10 \%$ hematocrit were treated by a slow flux of $t$-BOOH for $120 \mathrm{~min}$ (flux rate, $0.7 \mu \mathrm{mol} / \mathrm{min}$ ) but with a cyclic 4-min time without exposure to the oxidant. At the indicated times, aliquots of sample were collected for HbSSG (triangle), membrane GSSP (circle), and GSSG (square) determination both from the treatment vessel and from a collection point not exposed to the oxidant (4 min after). Times of analysis from the treatment vessel: $0,30,60$, 90 , and $120 \mathrm{~min}$. Times of analysis of samples not exposed to the oxidants: 34, 64, 94, $150 \mathrm{~min}$. Data are the mean of four separate experiments (Giustarini et al. 2019)

The results of a clinical study, where the levels of HbSSG were measured in erythrocytes of healthy people $(n=21)$ and in maintenance hemodialysis (HD) patients $(n=33)$, are also reported in Table 1. We found that GSSP were $46 \%$ higher in HD patients than in age-matched healthy controls. It is worthy of note that a significant increase in cysteinylated hemoglobin (CySSHb) in HD patients was also observed (38.3 vs $11.5 \mathrm{pmol} / \mathrm{mg} \mathrm{Hb} ; p<0.001$ ) and that RBCs from $\mathrm{HD}$ patients contained twice as much CySSHb than HbSSG (Khazim et al. 2013).

Rat hemoglobin possesses some extra-reactive $-\mathrm{SH}$ groups that make this protein exceptionally susceptible to $S$-glutathionylation under pro-oxidative conditions (Rossi 


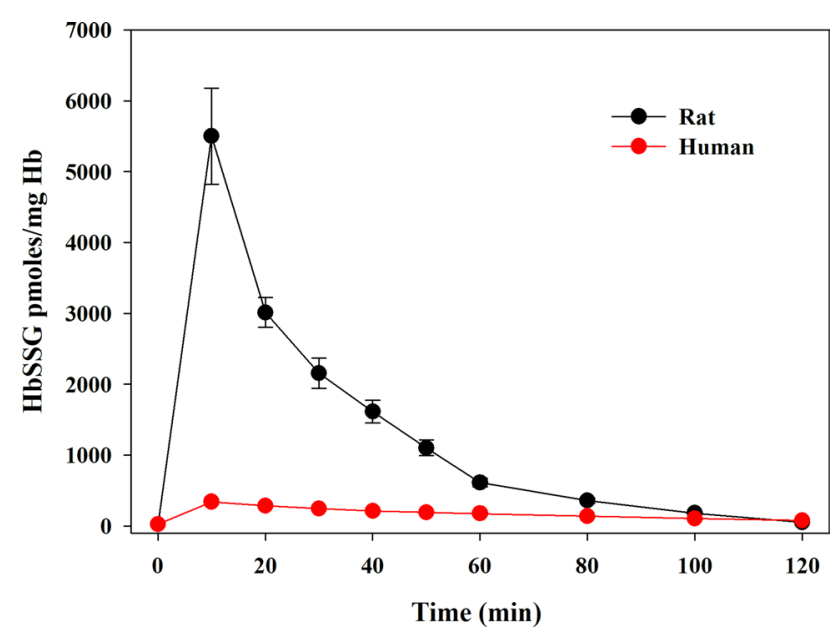

Fig. 4 Cytoplasmic HbSSG in human and rat RBCs treated with $t$-BOOH. RBCs were exposed to $1.5 \mathrm{mM} t$-BOOH (final concentration). At the indicated times, $S$-glutathionylated hemoglobin was measured in whole RBC lysates. Times of analysis: 0, 10, 20, 30, 40, $50,60,80,100$, and $120 \mathrm{~min}$. Data represent the means \pm SD of three separate experiments (Colombo et al. 2010)

et al. 2001). As shown in Fig. 4, an in vitro treatment of $\mathrm{RBCs}$ with $t$-BOOH induced a dramatic increase in HbSSG in rat samples but not in human ones. This particular susceptibility was observed also in some mice strains (Giustarini et al. 2006). $S$-glutathionylation of hemoglobin does not interfere with the allosteric capacity of hemoglobin to bind and transport oxygen. It can be thus interpreted as an extra antioxidant defense that RBCs of these animal species can exploit.

\section{GSSP in platelets and white blood cells}

Basal levels of GSSP in platelets from healthy humans measured with this protocol were $0.046 \pm 007 \mathrm{nmol} / 10^{9} \mathrm{plt}$ (Table 1). Treatment of platelets with disulfiram (a drug used to prevent alcoholism that has a reactive disulfide bridge in his structure) induced a dose-dependent increase in GSSP. When platelets were exposed to $1 \mathrm{mM}$ disulfiram, irreversible formation of GSSP occurred, with all cytosolic GSH bound to proteins to form GSSP. Instead, at lower concentrations of the drug, the recovery of both GSH and GSSP within $1 \mathrm{~h}$ was observed. Interestingly, the concentration of GSSP was shown to greatly affect platelet aggregation, indicating that P-SH have a key role in platelet activity. In fact, ADP-induced platelet aggregation was found to be inversely correlated with GSSP Fig. 5 (Rossi et al. 2006b). Actin can play a role in this process. Indeed, we found that, after treatment with disulfiram, actin is largely $S$-glutathionylated, probably because it has a solvent-exposed and extremely reactive Cys residue at position 374 that is susceptible to $S$-glutathionylation (Dalle-Donne et al. 2003).

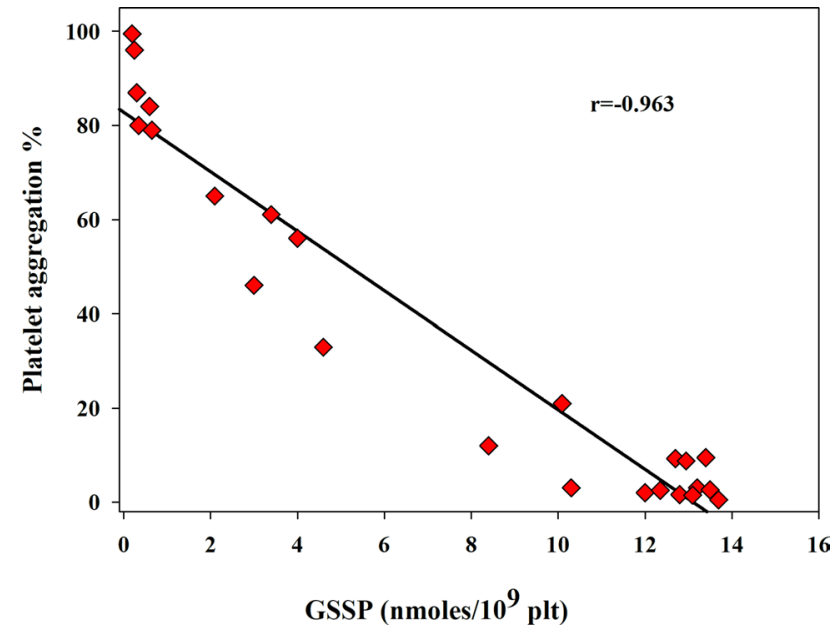

Fig. 5 Correlation between GSSP concentration and the percentage of platelet aggregation. Human platelets were exposed to $0.1,0.3$, and $1 \mathrm{mM}$ disulfiram. Platelet aggregation was initiated by the addition of $\operatorname{ADP}(10 \mu \mathrm{M}$, final concentration) and was monitored for $10 \mathrm{~min}$ by continuous recording of light transmission in a platelet aggregometer (Rossi et al. 2006a)

Basal levels of GSSP in white blood cells were rather difficult to measure because, after treatment with NEM (which is necessary to avoid artifacts), it is not easy to separate them from other blood components. As a matter of fact, we have not been able so far to separate lymphocytes and polymorphonuclear cells using common techniques (separation based on distinct density differences) after treatment with NEM. Therefore, we can report only levels of GSSP on whole blood leukocytes.

\section{RSSP in cultured cells and solid tissues}

We recently applied the present protocol to measure GSSP levels in several cell lines (Giustarini et al. 2015). Table 3 shows that GSSP levels in different cell lines fall in the range $14.0 \pm 3.3 \mathrm{pmol} / \mathrm{mg}$ of protein for human prostate cancer-derived bicalutamide-resistant cells (LNCap-Rbic) to $140 \pm 26 \mathrm{pmol} / \mathrm{mg}$ of protein in human glioblastomaderived cells (U87). In all the analyzed samples, the treatment with the oxidant drug disulfiram induced a remarkable dose-dependent increase in GSSP even at very low concentrations $(20 \mu \mathrm{M}$ or even less). The levels we measured are in agreement with those measured by Hansen et al. (Hansen et al. 2009), who found very low levels of GSSP also in HEK and HeLa cells, with values of a factor of 1000 below the value of total protein disulfides (i.e., PSSP + GSSP). Analogously, very low levels of GSSP (i.e., $57 \pm 42 \mathrm{nmol} /$ $\mathrm{mg}$ protein) were measured in rat liver by means of LC-MS/ MS (Bukowski et al. 2015). Levels of GSSP in solid tissues from rats at different ages are reported in Table 4. These values well agree with those reported by other research groups 
Table 3 Levels of GSSP in several cell lines under basal conditions and after a 15-min treatment with the pro-oxidant drug disulfiram

\begin{tabular}{lcc}
\hline Cell line & Control & $20 \mu$ M Disulfiram \\
\hline BAEC $^{\text {a }}$ & $110 \pm 17$ & $2378 \pm 67$ \\
HUVEC & $24.3 \pm 1.2$ & $476 \pm 54$ \\
Panc-1 & $87.1 \pm 10$ & $1423 \pm 96$ \\
NT2-D1 & $27.8 \pm 3.0$ & $86.3 \pm 11.2$ \\
A549 & $50.1 \pm 7.5$ & $96.9 \pm 5.5$ \\
RD & $107 \pm 3$ & $238 \pm 31$ \\
HEK & $47.3 \pm 3.6$ & $284 \pm 19$ \\
T98 & $330 \pm 41$ & $379 \pm 22$ \\
HaCaT & $20.6 \pm 1.4$ & $85.1 \pm 6.3$ \\
U87 & $140 \pm 26$ & $427 \pm 16$ \\
IMR-90 & $28.3 \pm 3.7$ & $493 \pm 75$ \\
BRC-230 & $26.4 \pm 2.4$ & $269 \pm 32$ \\
MCF-7 & $33.9 \pm 3.0$ & $186 \pm 11$ \\
A 375 & $233 \pm 13$ & $11,050 \pm 715$ \\
LNCaP & $20.7 \pm 7.1$ & $45.9 \pm 1.1$ \\
LNCaP-Rbic & $14.0 \pm 3.3$ & $32.2 \pm 2.6$ \\
\hline
\end{tabular}

Data (expressed as pmoles $/ \mathrm{mg}$ protein) are the mean $\pm \mathrm{SD}, n=3$

${ }^{a} B A E C$ bovine aortic endothelial cells, HUVEC human umbilical vein endothelial cells, Panc- 1 human pancreatic carcinoma-derived cells, NT2-D1 human pluripotent embryonal carcinoma-derived cells, A549 human lung carcinoma-derived cells, $R D$ human rhabdomyosarcomaderived cells, HEK 293 human embryonic kidney-derived cells, T98G human brain glioblastoma-derived cells, $\mathrm{HaCaT}$ human spontaneously immortalized keratinocyte cells, U87 human glioblastomaderived cells, IMR-90 human embryonic lung-derived fibroblasts, $B R C-230$ human breast cancer-derived cells, $M C F-7$ human breast cancer-derived cells, A375 human melanoma-derived cells, LNCaP human prostate cancer-derived cells, LNCaP-Rbic bicalutamideresistant cells derived from $\mathrm{LNCaP}$

Table 4 Values for GSSP in solid rat tissues at different ages

\begin{tabular}{llll}
\hline Tissue & 3 months & 9 months & 20 months \\
\hline Liver & $4.44 \pm 0.80$ & $4.54 \pm 0.60$ & $5.65 \pm 0.60$ \\
Kidney & $2.14 \pm 0.30$ & $1.76 \pm 0.11$ & $1.76 \pm 0.61$ \\
Lung & $2.12 \pm 0.32$ & $1.89 \pm 0.24$ & $2.81 \pm 0.62^{*, \#}$ \\
Heart & $1.06 \pm 0.07$ & $1.13 \pm 0.11$ & $1.72 \pm 0.60^{* *, \#}$ \\
Spleen & $6.45 \pm 0.53$ & $5.09 \pm 0.88$ & $8.68 \pm 0.60^{* *, \# \#}$ \\
Testis & $1.48 \pm 0.20$ & $1.51 \pm 0.05$ & $0.90 \pm 0.61$ \\
Brain & $5.81 \pm 0.42$ & $5.96 \pm 0.77$ & $8.08 \pm 0.61^{*, \#}$ \\
\hline
\end{tabular}

Data are expressed as $\mathrm{nmol} / \mathrm{g}$ wet tissue and are the mean $\pm \mathrm{SD}$, $n=4$ for each study group. ${ }^{*} p<0.05$ vs 3 -month-old rats; ${ }^{*} p<0.01$ vs 3 -month-old rats; $\# p<0.05$ vs 9-month-old rats; \#\#p<0.01 vs 9-month-old rats

(Bukowski et al. 2015; Arambasic et al. 2013) that found $57 \pm 42 \mathrm{nmol} / \mathrm{mg}$ protein GSSP in rat liver and $1.75 \mu \mathrm{M}$ GSSP in rat kidneys, respectively. GSSP were found to be significantly increased in some organs (lung, heart, spleen, brain) with aging (Giustarini et al. 2011), thus supporting a role of free radicals in this physio-pathological process (Viña et al. 2007).

\section{RSSP in plasma}

Plasma content of RSSP is very different from the intracellular one both in terms of concentration and species of LMM-SH bound to proteins. In fact, plasma is quite poor in antioxidants and glutathione reductase is present only in traces, which probably derive from cellular disruption. As for thiols, plasma is characteristically rich in their disulfide forms and contains not only GSSP but also $S$-cysteinylated (CySSP) and $S$-homocysteinylated (HcySSP) proteins. In addition, also protein-mixed disulfides with cysteinyl glycine (CyGlySSP) and $\gamma$-glutamylcysteine ( $\gamma$-GluCySSP) are generally found (Turell et al. 2013).

The values for different RSSP measured in 22 healthy controls with the present protocol are reported in Table 5 (Fanti et al. 2015). These values are in agreement with those reported by others (Grintzalis et al. 2014). For some of these (CySSP, CyGlySSP, HcySSP), we observed a significant increase in maintenance HD patients. CySSP concentration resulted to be directly related to plasma neutrophil gelatinase-associated lipocalin (NGAL) in maintenance HD patients, suggesting functional coupling of thiol stress and acute-phase response in uremia. High circulating levels of NGAL are only in part the consequence of impaired renal elimination of the protein, as they also result from increased systemic production in response to chronic kidney diseaserelated inflammation and possibly to iron supplementation (Bolignano et al. 2009; Chakraborty et al. 2012).

\section{Conclusion}

Post-translational modification of thiol groups is considered to be one of the main processes involved in redox signaling. Given its reversibility, $S$-glutathionylation is supposed to have an important role for the redox switching of proteins, thus altering their function (Mieyal and Chock 2012). Additionally, $S$-glutathionylated proteins are currently investigated as powerful biomarkers of oxidative stress. Nevertheless, their analysis is not easy, since their concentration can be overestimated as a result of the oxidation of thiols during the pre-analytical step. Here, we describe a protocol that avoids virtually all methodological problems by protecting the $-\mathrm{SH}$ group from its artificial oxidation. By applying this procedure, we have been able to demonstrate that the basal levels of GSSP are very low in most biological samples, with the exception of the extracellular compartment. Our values are similar to those reported by other research groups for some tissues (e.g., plasma, rat liver, and kidney) but are significantly lower for HbSSG. It is possible that blood is particularly prone to GSH auto-oxidation by virtue of the presence of oxygen and iron in the heme group. Therefore, the need to spike the blood samples as soon as possible with 
Table 5 Values for RSSP in plasma of healthy people and in maintenance hemodialysis (MHD) patients

\begin{tabular}{|c|c|c|c|c|c|}
\hline Sample & $\mathrm{CySSP}^{\mathrm{a}}$ & CyGlySSP & HcySSP & $\gamma$-GluCySSP & GSSP \\
\hline Healthy humans $(n=24)$ & $163(150-195)$ & $15.0(13.3-18.1)$ & $8.23(6.45-9.96)$ & $1.55(1.31-1.71)$ & $3.11(2.66-3.38)$ \\
\hline $\operatorname{MHD}(n=71)$ & $216 * *(182-254)$ & $21.0 * *(16.5-25.5)$ & $18.5^{* *}(14.9-23.4)$ & $1.51(1.22-1.78)$ & $3.01(2.07-3.91)$ \\
\hline
\end{tabular}

Data are the median and are expressed as $\mu \mathrm{M}$. ** $p<0.001$ vs healthy humans

${ }^{a} C y S S P$ protein-mixed disulfides with cysteine, $C y G l y S S P$ protein-mixed disulfides with cysteinyl glycine, $H c y S S P$ protein-mixed disulfide with homocysteine, $\gamma$-GluCySSP protein-mixed disulfides with $\gamma$-glutamylcysteine, GSSP protein-mixed disulfides with GSH

the suitable GSH blocking agent is particularly evident. We demonstrated that GSSP represent a sensitive biomarker of oxidative stress, since their concentration increases significantly also at low concentrations of oxidants (Rossi et al. 2006a; Giustarini et al. 2019). However, this sensitivity dramatically decreases when GSSP are overestimated. The protocol can be applied to all biological samples and the quantification by HPLC with fluorometric detector allows the discrimination among the different LMM-SH involved in the RSSP formation. Obviously, this method is characterized by pros and cons. The main pro is that it is quantitative and can estimate with good precision and accuracy the total amount of GSSP in a biological sample. The main con is that it cannot discriminate among the various GSSP, and thus, it is impossible to identify every single protein undergoing $S$-glutathionylation.

Funding Open access funding provided by Università degli Studi di Siena within the CRUI-CARE Agreement.

\section{Declarations}

Conflict of interest The authors declare that they have no conflict of interest.

Ethical approval All animal handling procedures were carried out in accordance with the European Community guidelines for the use of laboratory animals. The experiments were authorized by the local ethical committee of the University of Siena. The clinical study with hemodialyzed patients was approved by the Veteran Administration Research and Development Office Institutional Review Board and The University of Texas Health Science Center San Antonio. Written informed consent was obtained from every subject. The clinical studies with healthy controls were conducted on volunteers after oral consent.

Open Access This article is licensed under a Creative Commons Attribution 4.0 International License, which permits use, sharing, adaptation, distribution and reproduction in any medium or format, as long as you give appropriate credit to the original author(s) and the source, provide a link to the Creative Commons licence, and indicate if changes were made. The images or other third party material in this article are included in the article's Creative Commons licence, unless indicated otherwise in a credit line to the material. If material is not included in the article's Creative Commons licence and your intended use is not permitted by statutory regulation or exceeds the permitted use, you will need to obtain permission directly from the copyright holder. To view a copy of this licence, visit http://creativecommons.org/licenses/by/4.0/.

\section{References}

Al-Abed Y, VanPatten S, Li H, Lawson JA, FitzGerald GA, Manogue KR, Bucala R (2001) Characterization of a novel hemoglobinglutathione adduct that is elevated in diabetic patients. Mol Med 7(9):619-623

Arambašić J, Mihailović M, Uskoković A, Dinić S, Grdović N, Marković J, Poznanović G, Bajec D, Vidaković M (2013) Alphalipoic acid upregulates antioxidant enzyme gene expression and enzymatic activity in diabetic rat kidneys through an $O$-GlcNAcdependent mechanism. Eur J Nutr 52:1461-1473. https://doi.org/ 10.1007/s00394-012-0452-Z

Bolignano D, Coppolino G, Romeo A, De Paola L, Buemi A, Lacquaniti A, Nicocia G, Lombardi L, Buemi M (2009) Neutrophil gelatinase associated lipocalin (NGAL) reflects iron status in haemodialysis patients. Nephrol Dial Transplant 24:3398-3403. https://doi.org/10.1093/ndt/gfp310

Bradford MM (1976) A rapid and sensitive method for the quantitation of microgram quantities of protein utilizing the principle of protein-dye binding. Anal Biochem 72:248-225

Brunori M, Bellelli A, Giardina B (1982) Hemoglobins from Wistar rat: crystallization of components and intraerythrocytic crystals. Eur J Biochem 129:459-463

Bukowski MR, Bucklin C, Picklo MJ (2015) Quantitation of protein $S$-glutathionylation by liquid chromatography-tandem mass spectrometry: correction for contaminating glutathione and glutathione disulfide. Anal Biochem 469:54-64. https://doi. org/10.1016/j.ab.2014.10.002

Candiano G, Petretto A, Bruschi M, Santucci L, Dimuccio V, Prunotto M, Gusmano R, Urbani A, Ghiggeri GM (2009) The oxido-redox potential of albumin methodological approach and relevance to human diseases. J Proteomics 73:188-195. https:// doi.org/10.1016/j.jprot.2009.06.006

Chakraborty S, Kaur S, Guha S, Batra SK (2012) The multifaceted roles of neutrophil gelatinase associated lipocalin (NGAL) in inflammation and cancer. Biochim Biophys Acta 1826:129-169. https://doi.org/10.1016/j.bbcan.2012.03.008

Chen H-JC, Lin W-P, Chiu S-D, Fan C-H (2014) Multistage mass spectrometric analysis of human hemoglobin glutathionylation: correlation with cigarette smoking. Chem Res Toxicol 27(5):864-872. https://doi.org/10.1021/tx5000359

Colombo G, Dalle-Donne I, Giustarini D, Gagliano N, Portinaro N, Colombo R, Rossi R, Milzani A (2010) Cellular redox potential and hemoglobin $S$-glutathionylation in human and rat erythrocytes: `a comparative study. Blood Cells Mol Dis 44:133-139

Dalle-Donne I, Giustarini D, Rossi R, Colombo R, Milzani A (2003) Reversible $S$-glutathionylation of $\mathrm{Cys}^{374}$ regulates actin filament 
formation by inducing structural changes in the actin molecule. Free Radic Biol Med 34:23-32. https://doi.org/10.1016/s08915849(02)01182-6

Dalle-Donne I, Milzani A, Gagliano N, Colombo R, Giustarini D, Rossi R (2008) Molecular mechanisms and potential clinical significance of $S$-glutathionylation. Antioxid Redox Signal 10:445-473. https://doi.org/10.1089/ars.2007.1716

Fanti P, Giustarini D, Rossi R, Cunningham SE, Folli F, Khazim K, Cornell J, Matteucci E, Bansal S (2015) Dietary intake of proteins and calories is inversely associated with the oxidation state of plasma thiols in end-stage renal disease patients. J Ren Nutr 25:494-503. https://doi.org/10.1053/j.jrn.2015.06.003

Garel MC, Beuzard Y, Thillet J, Domenget C, Martin J, Galacteros F, Rosa J (1982) Binding of 21 thiol reagents to human hemoglobin in solution and in intact cells. Eur J Biochem 123:513519. https://doi.org/10.1111/j.1432-1033.1982.tb06561.x

Giustarini D, Dalle-Donne I, Colombo R, Petralia S, Giampaoletti S, Milzani A, Rossi R (2003) Protein glutathionylation in erythrocytes. Clin Chem 49:327-330. https://doi.org/10.1373/49.2.327

Giustarini D, Dalle-Donne I, Cavarra E, Fineschi S, Lungarella G, Milzani A, Rossi R (2006) Metabolism of oxidants by blood from different mouse strains. Biochem Pharmacol 71:17531764. https://doi.org/10.1016/j.bcp.2006.03.015

Giustarini D, Dalle-Donne I, Milzani A, Rossi R (2011) Low molecular mass thiols, disulfides and protein mixed disulfides in rat tissues: influence of sample manipulation, oxidative stress and ageing. Mech Ageing Dev 132:141-148

Giustarini D, Galvagni F, Tesei A, Farolfi A, Zanoni M, Pignatta S, Milzani A, Marone IM, Dalle-Donne I, Nassini R, Rossi R (2015) Glutathione, glutathione disulfide and $S$-glutathionylated proteins in cell cultures. Free Radic Biol Med 89:972-981. https://doi.org/ 10.1016/j.freeradbiomed.2015.10.410

Giustarini D, Galvagni F, Orlandini M, Fanti P, Rossi R (2016) Immediate stabilization of human blood for delayed quantification of endogenous thiols and disulfides. J Chromatogr B Analyt Technol Biomed Life Sci 1019:51-58

Giustarini D, Colombo G, Garavaglia ML, Astori E, Portinaro NM, Reggiani F, Badalamenti S, Aloisi AM, Santucci A, Rossi R, Milzani A, Dalle-Donne I (2017) Assessment of glutathione/glutathione disulphide ratio and $S$-glutathionylated proteins in human blood, solid tissues, and cultured cells. Free Radic Biol Med 112:360-375. https://doi.org/10.1016/j.freeradbiomed.2017.08.008

Giustarini D, Dalle-Donne I, Milzani A, Braconi D, Santucci A, Rossi R (2019) Membrane skeletal protein $S$-glutathionylation in human red blood cells as index of oxidative stress. Chem Res Toxicol 32:1096-1102. https://doi.org/10.1021/acs.chemrestox.9b00030

Grek CL, Zhang J, Manevich Y, Townsend DM, Tew KD (2013) Causes and consequences of cysteine $S$-glutathionylation. J Biol Chem 288:26497-26504. https://doi.org/10.1074/jbc.R113. 461368

Grintzalis K, Papapostolou I, Zisimopoulos D, Stamatiou I, Georgiou CD (2014) Multiparametric protocol for the determination of thiol redox state in living matter. Free Radic Biol Med 74:85-98. https://doi.org/10.1016/jfreeradbiomed.2014.06.024

Hansen RE, Roth D, Winther JR (2009) Quantifying the global cellular thiol-disulfide status. Proc Natl Acad Sci USA 106:422-427. https://doi.org/10.1073/pnas.0812149106

Khazim K, Giustarini D, Rossi R, Verkaik D, Cornell JE, Cunningham SE, Mohammad M, Trochta K, Lorenzo C, Folli F, Bansal S, Fanti $\mathrm{P}$ (2013) Glutathione redox potential is low and glutathionylated and cysteinylated hemoglobin levels are elevated in maintenance hemodialysis patients. Transl Res 162:16-25. https://doi.org/10. 1016/j.trsl.2012.12.014

Mandal AK, Woodi M, Sood V, Krishnaswamy PR, Rao A, Ballal S, Balaram P (2007) Quantitation and characterization of glutathionyl haemoglobin as an oxidative stress marker in chronic renal failure by mass spectrometry. Clin Biochem 40:986-994. https:// doi.org/10.1016/j.clinbiochem.2007.05.006

Mieyal JJ, Chock PB (2012) Posttranslational modification of cysteine in redox signaling and oxidative stress: focus on $S$-glutathionylation. Antioxid Redox Signal 16:471-475. https://doi.org/10.1089/ ars.2011.4454

Muscat JE, Kleinman W, Colosimo S, Muir A, Lazarus P, Park J, Richie JP (2004) Enhanced protein glutathiolation and oxidative stress in cigarette smokers. Free Radical Biol Med 36(4):464-470. https://doi.org/10.1016/j.freeradbiomed.2003.11.018

Naito C, Kajita M, Niwa T (1999) Determination of glutathionyl hemoglobin in hemodialysis patients using electrospray ionization liquid chromatography-mass spectrometry. J Chromatogr B Biomed Sci Appl 731:121-124. https://doi.org/10.1016/s0378-4347(99)00139-5

Niwa T (2007) Protein glutathionylation and oxidative stress. J Chromatogr B 855:59-65. https://doi.org/10.1016/j.jchromb.2006.12.029

Pastore A, Ciampalini P, Tozzi G, Pecorelli L, Passarelli C, Bertini E, Piemonte F (2012) All glutathione forms are depleted in blood of obese and type 1 diabetic children. Pediatr Diabetes 13:272-277. https://doi.org/10.1111/j.1399-5448.2011.00806.x

Piemonte F, Pastore A, Tozzi G, Tagliacozzi D, Santorelli FM, Carrozzo R, Casali C, Damiano M, Federici G, Bertini E (2001) Glutathione in blood of patients with Friedreich's ataxia. Eur J Clin Invest 31:1007-1011. https://doi.org/10.1046/j.1365-2362.2001.00922.x

Rossi R, Milzani A, Dalle-Donne I, Giannerini F, Giustarini D, Lusini L, Colombo R, Di Simplicio P (2001) Different metabolizing ability of thiol reactants in human and rat blood. J Biol Chem 276:7004-7010. https://doi.org/10.1074/jbc.M005156200

Rossi R, Milzani A, Dalle-Donne I, Giustarini D, Lusini L, Colombo R, Di Simplicio P (2002) Blood glutathione disulfide: in vivo factor or in vitro artifact? Clin Chem 48:742-753. https://doi.org/10. 1016/j.jprot.2009.06.006

Rossi R, Dalle-Donne I, Milzani A, Giustarini D (2006a) Oxidized forms of glutathione in peripheral blood as biomarkers of oxidative stress. Clin Chem 52:1406-1414. https://doi.org/10.1373/ clinchem.2005.061408

Rossi R, Giustarini D, Dalle-Donne I, Milzani A (2006b) Protein $S$-glutathionylation and platelet anti-aggregating activity of disulfiram. Biochem Pharmacol 72:608-615. https://doi.org/10.1016/j.bcp. 2006.05.021

Schafer FQ, Buettner GR (2001) Redox environment of the cell as viewed through the redox state of the glutathione disulfide/ glutathione couple. Free Radic Biol Med 30:1191-1212. https://doi. org/10.1016/s0891-5849(01)00480-4

Schepens MA, Roelofs HM, Peters WH, Wanten GJ (2006) No evidence for oxidative stress in patients on home parenteral nutrition. Clin Nutr 25:939-948. https://doi.org/10.1016/j.clnu.2006.05.001

Sengupta S, Chen H, Togawa T, DiBello PM, Majors AK, Büdy B, Ketterer ME, Jacobsen DW (2001) Albumin thiolate anion is an intermediate in the formation of albumin-S-S-homocysteine. J Biol Chem 276:30111-30117. https://doi.org/10.1074/jbc.M104324200

Takayama F, Tsutsui S, Horie M, Shimokata K, Niwa T (2001) Glutathionyl hemoglobin in uremic patients undergoing hemodialysis and continuous ambulatory peritoneal dialysis. Kidney Int Suppl 78:S155S158. https://doi.org/10.1046/j.1523-1755.2001.59780155.x

Turell L, Radi R, Alvarez B (2013) The thiol pool in human plasma: the central contribution of albumin to redox processes. Free Radic Biol Med 65:244-253. https://doi.org/10.1016/j.freeradbiomed. 2013.05.050

Viña J, Borrás C, Miquel J (2007) Theories of ageing. IUBMB Life 59:249-254. https://doi.org/10.1080/15216540601178067

Publisher's Note Springer Nature remains neutral with regard to jurisdictional claims in published maps and institutional affiliations. 